\title{
ChemComm
}

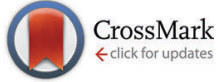

Cite this: Chem. Commun., 2015 51,714

Received 24th September 2014, Accepted 11th November 2014

DOI: $10.1039 / c 4 c c 07554 d$

www.rsc.org/chemcomm

\section{Formation of a quasi-solid structure by intercalated noble gas atoms in pores of $\mathrm{Cu}^{\prime}-\mathrm{MFU}-4$ l metal-organic framework $\dagger$}

\author{
Oxana V. Magdysyuk, ${ }^{\text {a }}$ Dmytro Denysenko, ${ }^{\text {b }}$ Ingrid Weinrauch, ${ }^{c}$ Dirk Volkmer, ${ }^{\text {b }}$ \\ Michael Hirscher ${ }^{c}$ and Robert E. Dinnebier ${ }^{\star a}$
}

\begin{abstract}
The primary adsorption sites for $\mathrm{Kr}$ and $\mathrm{Xe}$ within the large-pore metal-organic framework $\mathrm{Cu}^{\prime}-\mathrm{MFU}-4 \mathrm{l}$ have been investigated by high-resolution synchrotron powder diffraction, revealing an enormous number of adsorption sites: in total, 10 crystallographically different positions for $\mathrm{Xe}$ and 8 positions for $\mathrm{Kr}$ were localized, the first five of which are located near metal atoms and the organic linker, and the remaining sites form a second adsorption layer in the pores.
\end{abstract}

Although noble gases have a high potential in industrial applications (e.g. fluorescent light lamps, thermal insulation, excimer lasers, ionization chambers, general inhalation anesthetics), their practical use is restricted by their high costs due to the energetically expensive procedure of their separation. A mixture of krypton and xenon is obtained by cryogenic distillation of air, which initially contains only 1.14 ppm of krypton and 0.087 ppm of xenon. ${ }^{1}$ Further separation of noble gases from their mixture requires additional distillation. Development of porous metal-organic frameworks (MOFs) for adsorption-enhanced separation of noble gases can considerably decrease costs and extend practical applications. Another promising application of MOFs is the storage and separation of radioactive noble gases. The gaseous products from nuclear reactors, nuclear fuel reprocessing plants, and from the production of medical isotopes contain significant amounts of radioactive krypton and xenon, which are difficult to separate and to confine because they are chemically inert and relatively insoluble in water. ${ }^{1}$ Their storage and transportation can be substantially improved by using highly selective MOFs with good storage capacity.

The development of MOFs with specific adsorption properties requires deep insight into the factors controlling noble gas adsorption, primarily through experimental investigations of the interaction between adsorbent and noble gas atoms. It is still largely unclear, how

\footnotetext{
${ }^{a}$ Max Planck Institute for Solid State Research, Heisenbergstr. 1, Stuttgart, Germany. E-mail: R.Dinnebier@fkf.mpg.de

${ }^{b}$ Augsburg University, Institute of Physics, Chair of Solid State and Materials Chemistry, Universitätsstr. 1, Augsburg, Germany

${ }^{c}$ Max Planck Institute for Intelligent Systems, Heisenbergstr. 3, Stuttgart, Germany $\dagger$ Electronic supplementary information (ESI) available: XRPD, crystallographic data, and adsorption/desorption measurements. See DOI: 10.1039/c4cc07554d
}

the MOF structure and metal sites influence the noble gas adsorption properties. Despite the fact that the major adsorption sites and their binding energies are the key features of a system that determines its adsorption properties at a given temperature and pressure, only four X-ray or neutron diffraction studies targeting at the adsorption sites of noble gases in MOFs were performed so far. ${ }^{2-5}$ On the other hand, the possibility of using MOFs for noble gas storage and separation caused extensive theoretical investigations of key factors determining noble gas adsorption and separation over last a few years, ${ }^{6}$ as well as numerous experimental $\mathrm{Xe}$ and $\mathrm{Kr}$ adsorption studies. ${ }^{4,5,7,8}$

The present communication reports the results of the structural investigation on the guest noble gases $\mathrm{Xe}$ and $\mathrm{Kr}$ in $\mathrm{Cu}^{\mathrm{I}}-\mathrm{MFU}-4 l$, $\mathrm{Cu}_{2.13} \mathrm{Zn}_{2.87} \mathrm{Cl}_{0.52}(\mathrm{HCOO})_{1.35}(\mathrm{BTDD})_{3} ; \mathrm{H}_{2}$-BTDD = (bis $(1 H-1,2,3-$ triazolo-[4,5- $b],[4,5-i])$ dibenzo-[1,4]-dioxin), supported by adsorption and thermal desorption measurements. $\mathrm{Cu}^{\mathrm{I}}-\mathrm{MFU}-4 l$ is isostructural to MFU-4l, the latter constructed from $\left[\mathrm{Zn}_{5} \mathrm{Cl}_{4}\right]^{6+}$ secondary building units (SBUs) and bis-triazolate BTDD $^{2-}$ ligands. ${ }^{9}$ MFU- $4 l$ contains two differently sized cavities alternating in three dimensions, which differ by the orientation of chloride ligands and by the relative orientations of the organic linkers (Fig. 1). The $\mathrm{Cu}$ atoms in $\mathrm{Cu}^{\mathrm{I}}$-MFU- $4 l$ randomly substitute $\sim 50 \%$ of the peripheral $\mathrm{Zn}$ atoms of the $\left[\mathrm{Zn}_{5} \mathrm{Cl}_{4}\right]^{6+}$ SBUs. ${ }^{10}$ Only approx. $30 \%$ of the peripheral zinc ions are coordinated by chloride anions, whereas the major part in the $\mathrm{Zn}$ ions are coordinated by formate ligands. Three-fold coordinated $\mathrm{Cu}^{\mathrm{I}}$ ions represent unsaturated open metal sites after evacuation of $\mathrm{Cu}^{\mathrm{I}}-\mathrm{MFU}-4 l$. $\mathrm{Cu}^{\mathrm{I}}-\mathrm{MFU}-4 l$ possesses many unique adsorption properties, including extremely strong and reversible chemisorption of $\mathrm{H}_{2}, \mathrm{~N}_{2}$, and $\mathrm{C}_{2} \mathrm{H}_{4} \cdot{ }^{10}$ Additionally to its high thermal stability, $\mathrm{Cu}^{\mathrm{I}}$-MFU- $4 l$ is stable in air and after prolonged evacuation, a key factor for technical applications.

In this communication we report on the unique adsorption of noble gases Xe and $\mathrm{Kr}$ by exceptional thermally and chemically stable $\mathrm{Cu}^{\mathrm{I}}-\mathrm{MFU}-4 l$, making it a promising candidate for industrial noble gas storage and separation.

X-ray powder diffraction (XRPD) measurements of Xe adsorption in $\mathrm{Cu}^{\mathrm{I}}-\mathrm{MFU}-4 l$ were performed at $250 \mathrm{~K}$ and $170 \mathrm{~K}$, of $\mathrm{Kr}$ adsorption at $250 \mathrm{~K}, 170 \mathrm{~K}$, and $130 \mathrm{~K}$ at different pressures $(5 \mathrm{kPa}, 10 \mathrm{kPa}$, $25 \mathrm{kPa}, 50 \mathrm{kPa}$, and $100 \mathrm{kPa}$ ) at the high-resolution diffractometer 


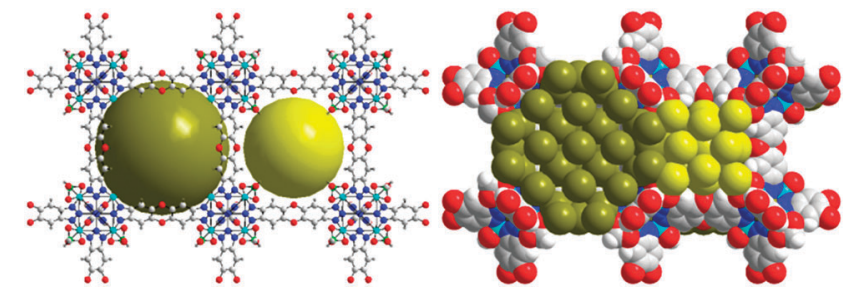

Fig. 1 (left) Crystal structure of MFU-4l with two types of alternating cavities: large and small; (right) $\mathrm{Cu}^{\prime}-\mathrm{MFU}-4 \mathrm{l}$ with all 10 positions of $\mathrm{Xe}$ occupied (van der Waals radii for all atoms).

ID31 at ESRF (Grenoble). ${ }^{11}$ Samples were evacuated in situ at $180{ }^{\circ} \mathrm{C}$ before gas loading, and validated by Rietveld refinement. ${ }^{12}$ Then they were cooled down to room temperature and exposed to Xe or $\mathrm{Kr}$ gas.

The noble gas adsorption behaviour of $\mathrm{Cu}^{\mathrm{I}}-\mathrm{MFU}-4 l$ was investigated under various pressures and temperatures and revealed the formation of a unique quasi-solid $\mathrm{Xe}$ and $\mathrm{Kr}$ structures in the cavities at temperatures above the corresponding boiling temperatures for Xe (5 K above boiling temperature) and $\mathrm{Kr}$ (10 K above boiling temperature).

With decreasing temperature and increasing gas pressure, up to 10 positions for $\mathrm{Xe}$ and up to 8 positions for $\mathrm{Kr}$ were located. There are five adsorption sites, which are closest to the framework, while the remaining sites form a second adsorption layer within the pores (Fig. 2). The main adsorption site I for both $\mathrm{Xe}$ and $\mathrm{Kr}$ atoms in $\mathrm{Cu}^{\mathrm{I}}-\mathrm{MFU}-4 l$ is the same as for MFU- $4 l^{3}$ (Fig. 2, I). It is located in the center of the three faces of $\mathrm{ZnN}_{3} \mathrm{Cl}$ (metal site) at approximately the same distances from the central (octahedral) and peripheral (tetrahedral) metal atoms of SBUs, and also close to the nitrogen atoms, which create a steric barrier between noble gas atoms and metal atoms. This adsorption site is the closest to the framework and provides the possibility to interact with the large part of framework for adsorbed noble gas atoms. The second adsorption site II interacts with a peripheral outer metal atom and formate ligands (coordinated statistically disordered $\mathrm{Zn}$ atoms, not shown in Fig. 2) and is close to adsorption site I at low pressures and high temperature, representing statistical disorder of adsorption site I, but moving away from the central metal atom and interacting only with the peripheral metal atom and framework atoms upon increasing the pressure (Fig. 2, II). Both adsorption sites I and II are located in the large cavities. The adsorption site III interacts with the unsaturated statistically distributed trigonal pyramidal $\mathrm{Cu}^{\mathrm{I}}$ open metal sites in the small cavities as well as with framework atoms (Fig. 2, III). The adsorption site IV is located near the center of the $\mathrm{C}_{4} \mathrm{O}_{2}$ 1,4-dioxane ring of the organic linker (Fig. 2, IV). The adsorption site $\mathrm{V}$ is disordered near oxygen atoms of the organic linker (Fig. 2, V). Oxygen atoms from carbon-oxygen bonds were found previously to be quite strong adsorption sites for argon, ${ }^{2}$ for $\mathrm{Kr}$ and for Xe. ${ }^{5}$ Further increasing of pressure (decreasing of temperature) results in the formation of a second adsorption layer in the large pores (Fig. 2, VI, VII, VIII), which consists of 3 different positions similar for both, Xe and $\mathrm{Kr}$ atoms. Two peripheral atomic positions of this second adsorption layer form the remarkable tungsten-type coordination around a central third position. The formation of a second adsorption layer in the small pores (two adsorption positions) was observed only for Xe atoms at $T=170 \mathrm{~K}$ and a pressure above $25 \mathrm{kPa}$ (corresponding to 0.2 relative pressure), showing that small and large pores are not equivalent for noble gas adsorption (Fig. 2, IX, X). The filling of accessible voids in the small pores is responsible for the weak inflection in the Xe adsorption isotherms (Fig. 3, middle). It can be seen that the main adsorption step for Xe is unusually steep and suggests highly selective filling of large pores (approx. 85\% of total pore volume which corresponds to the data obtained from XRPD measurements). This is probably the reason, why two separated steps are observed in the case of Xe adsorption. $\mathrm{Kr}$, in contrast, shows only one adsorption step with rather usual shape (Fig. 3, top). In the case of Kr adsorption at $130 \mathrm{~K}$, the small pore remains empty even at quite high pressure $(100 \mathrm{kPa}$, corresponding to 0.5 relative pressure, Fig. 3 , top). This fact looks more surprising taking into account the smaller kinetic radius of $\mathrm{Kr}$ atoms and can be explained by larger difference between the actual temperature of the measurement $(130 \mathrm{~K})$ and the boiling temperature of $\mathrm{Kr}(120 \mathrm{~K})$ in contrast to Xe $(170 \mathrm{~K}$ measurement temperature and $165 \mathrm{~K}$ boiling temperature). At highest loadings the large cavity adsorbs $c a .55$ atoms of Xe and $c a .70$ atoms of $\mathrm{Kr}$ in 83 available positions, providing a very dense packing of adsorbed noble gas atoms. Almost complete filling of large (and small) cavities of $\mathrm{Cu}^{\mathrm{I}}$-MFU- $4 l$ results into formation of quasi-solid structure by $\mathrm{Kr}$ and Xe atoms inside the cavities above their boiling temperature - a phenomenon, which to the best of our knowledge has not been reported before. The apparent increase of the freezing point for $\mathrm{Xe}$ and $\mathrm{Kr}$ is related to strong van der Waals interaction with the framework atoms.

For both $\mathrm{Xe}$ and $\mathrm{Kr}$ atoms, the coordinatively unsaturated $\mathrm{Cu}^{\mathrm{I}}$ sites from the peripheral part of the SBU are not the first occupied adsorption sites, and their filling starts only after the major adsorption site in the center of triangular faces of the $\mathrm{ZnN}_{3} \mathrm{Cl}$ tetrahedron is filled. It can be related with preferential filling of large cavities in $\mathrm{Cu}^{\mathrm{I}}$ MFU-4l, while $\mathrm{Cu}$ atoms are located in small cavities. On the other hand, the coordinatively unsaturated $\mathrm{Cu}^{\mathrm{II}}$ sites in large cavities of HKUST-1 are not coordinated by noble gas atoms even at the highest pressures applied in these experiments. ${ }^{4}$ In contrast, the coordinatively unsaturated $\mathrm{Ni}^{\mathrm{II}}$ and $\mathrm{Mg}^{\mathrm{II}}$ sites in $\mathrm{CPO}-27-\mathrm{Ni}$ and $\mathrm{CPO}-27-\mathrm{Mg}$ are (one of) the primary adsorption sites. ${ }^{5}$ Thus, the adsorption of noble gases critically depends on the type of metal ion in the SBU of the MOFs. This interesting phenomenon requires further structural investigation.

From the adsorption isotherms at different temperatures follows the high $\mathrm{Xe} / \mathrm{Kr}$ selectivity of 8.1 at $250 \mathrm{~K}$ and 6.3 at $280 \mathrm{~K}$, which correlates with selectivity from structural investigation of single gas adsorption. The large selectivity of $\mathrm{Cu}^{\mathrm{I}}-\mathrm{MFU}-4 l$ is based on enhanced xenon-framework interactions in comparison with the kryptonframework interactions, which relates to the higher polarizability of Xe atom, as well as to stronger interactions between adsorbed Xe atoms. The latter follows from the variation of the lattice parameters at constant temperature: the unit cell is contracting upon Xe adsorption, and the only observed case of expansion is connected with entering Xe into small pores at $170 \mathrm{~K}, 25 \mathrm{kPa}$ (as described in the ESI, $\dagger$ Tables S4 and S5). The corresponding contraction of the unit cell upon $\mathrm{Kr}$ adsorption is much smaller and is changing to 

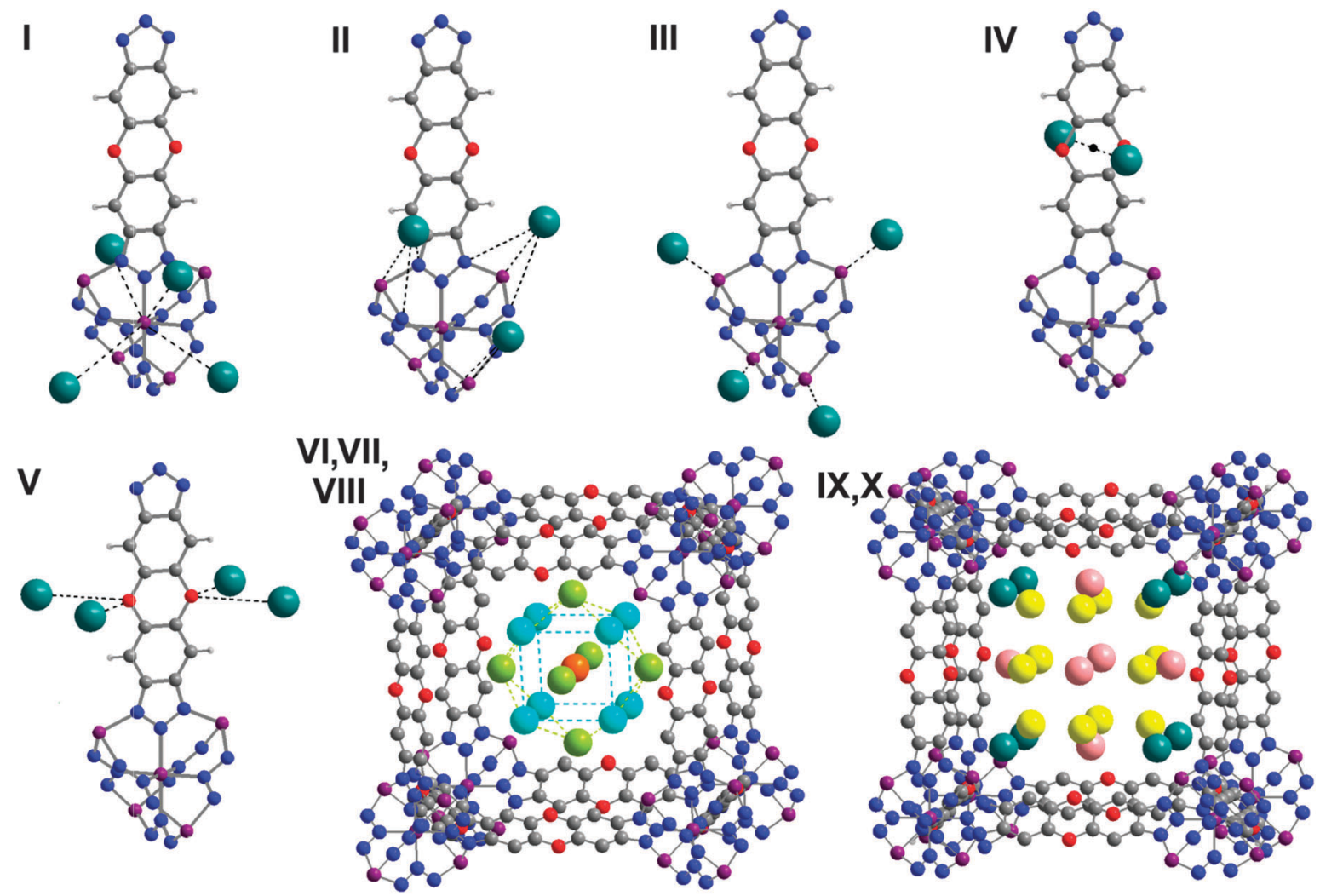

Fig. 2 Ten symmetry-independent adsorption sites occupied by Xe atoms (shown by large spheres) in the pores of Cu'-MFU-4l. Eight of these sites are also occupied by $\mathrm{Kr}$ atoms. These include three sites (I, II, and III) associated with secondary building unit, two sites (IV and V) associated with the organic linker, and five sites forming second adsorption layer within large (VI, VII, VIII) pores (three adsorption sites for both Xe and Kr) and small (IX, X) pores (two adsorption sites only for Xe, and adsorption site III for both, Xe and Kr). Framework atoms: carbon (gray), oxygen (red), nitrogen (blue), copper/zinc (violet).

expansion at high pressure due to the repulsion between adsorbed $\mathrm{Kr}$ atoms.

The isosteric heats of $\mathrm{Xe}$ and $\mathrm{Kr}$ adsorption in $\mathrm{Cu}^{\mathrm{I}}-\mathrm{MFU}-4 l$, determined from the adsorption isotherms (as described in the ESI, $\dagger$ Table S3), are nearly identical (within the experimental uncertainty of $c a . \pm 0.5 \mathrm{~kJ} \mathrm{~mol}^{-1}$ ) with the corresponding values determined previously for MFU- $4 l^{8}$ (Fig. 3, bottom). Therefore, no considerable chemical interaction between $\mathrm{Cu}^{\mathrm{I}}$ centers and Xe or Kr atoms takes place. This confirms the results of XRPD measurements, which have shown that unsaturated $\mathrm{Cu}^{\mathrm{I}}$ centers are not the strongest adsorption sites for Xe or Kr. Since van der Waals interaction between polarizable adsorbed noble gas atoms and the polarizable host framework is the main factor responsible for adsorption of noble gases, the initial adsorption in position I (having the largest geometrical area of contacts between adsorbed atom and framework) is responsible for slightly increased isosteric heat of adsorption at low-pressures (Fig. 3). The remaining four positions of the first adsorption layer have very similar binding strength to the framework, resulting into constant isosteric heat upon their filling. Low-temperature adsorption isotherms show, that for Xe at $170 \mathrm{~K}$ the pores are completely filled already at $c a .25 \mathrm{kPa}$ pressure (the adsorbed volume is nearly the same as at $165 \mathrm{~K}$, the normal boiling point of Xe). In the case of $\mathrm{Kr}$, in contrast, the complete pore filling can only be achieved at its boiling point $(120 \mathrm{~K})$, whereas at $130 \mathrm{~K}$ the small pores are not filled even at $95 \mathrm{kPa}$ pressure (Fig. 3). These observations are also in agreement with XRPD measurements.

Thermal desorption spectroscopy (TDS) measurements show two desorption maxima for Xe as well as for $\mathrm{Kr}$ (as described in the ESI, $\dagger$ Fig. S8 and S9). The desorption maximum at higher temperature can be attributed to the more strongly bound first adsorption layer, whereas the more weakly bound second adsorption layer desorbs already at lower temperature. In $\mathrm{Cu}^{\mathrm{I}}$-MFU- $4 l$ the noble gas desorption takes place in nearly the same temperature region as in MFU- $4 l^{8}$ showing no increased interaction of noble gases by $\mathrm{Cu}^{\mathrm{I}}$ centers.

The results of $\mathrm{Xe}$ and $\mathrm{Kr}$ adsorption on $\mathrm{Cu}^{\mathrm{I}}-\mathrm{MFU}-4 l$ are consistent with the adsorption behavior of the lighter argon atoms in MOF-5. ${ }^{2}$ In total, 8 different adsorption sites of argon in MOF-5 were found. Large and small cavities of MOF- 5 were also found to be not equivalent for noble gas adsorption, showing preferable filling of large cavities, and only one argon atom was located in the small cavity. This investigation is in contrast to the noble gas adsorption by HKUST- $1,{ }^{4}$ where all adsorption sites are associated with small cavities, and large cavities remain empty.

In summary, we report a detailed high-resolution XRPD study of Xe and $\mathrm{Kr}$ adsorption in cavities of $\mathrm{Cu}^{\mathrm{I}}-\mathrm{MFU}-4 l$, showing the formation of an almost "solid" structure of intercalated atoms inside the cavities. This quasi-solid structure of noble gas atoms 

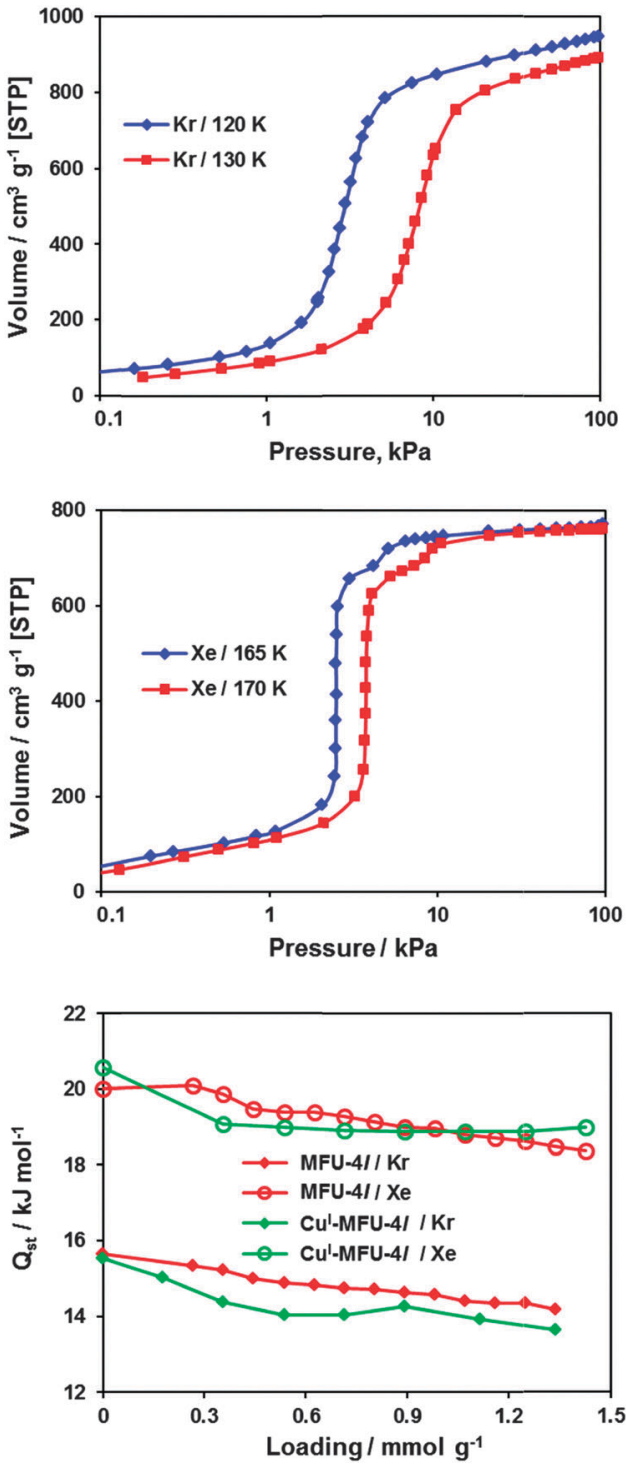

Fig. 3 Saturation adsorption isotherms for $\mathrm{Kr}$ (top) and $\mathrm{Xe}$ (middle) in $\mathrm{Cu}^{\prime}$ MFU $4 l$ in semilogarithmic scale, and dependencies of the isosteric heats of adsorption on loading for $\mathrm{Kr}$ and $\mathrm{Xe}$ in $\mathrm{Cu}^{\prime}-\mathrm{MFU}-4 \mathrm{l}$ in comparison to MFU $-4 l^{8}$ (bottom).

in cavities is stabilized above the boiling temperatures of the corresponding gases by van der Waals interaction. The presence of multiple adsorption sites with similar binding energies in $\mathrm{Cu}^{\mathrm{I}}-\mathrm{MFU}-4 l$ provides a great opportunity for $\mathrm{Xe}$ and $\mathrm{Kr}$ storage and separation due to homogeneous adsorption. The identification of the role of open metal sites and small cavities in the noble gas adsorption can be considered as a base for further engineering of MOFs in order to achieve maximal storage capacity and selectivity.

Support with synchrotron measurements at ESRF, ID31 (proposals ch3737, ch3878) to Dr C. Drathen (ESRF, Grenoble), Mr F. Adams and Mr T. Runcevski (Max Planck Institute for Solid State Research, Stuttgart) is gratefully acknowledged. Partial funding by the German
Research Foundation DFG within the priority program SPP 1362 is gratefully acknowledged.

\section{Notes and references}

1 Noble gases. Proc. Symp. on Noble gases, ed. R. E. Stanley and A. A. Moghissi, Las Vegas, NV, USA, 1973.

2 J. L. C. Rowsell, E. C. Spencer, J. Eckert, J. A. K. Howard and O. M. Yaghi, Science, 2005, 309, 1350.

3 A. Soleimani-Dorcheh, R. E. Dinnebier, A. Kuc, O. Magdysyuk, F. Adams, D. Denysenko, T. Heine, D. Volkmer, W. Donner and M. Hirscher, Phys. Chem. Chem. Phys., 2012, 14, 12892.

4 Z. Hulvey, K. V. Lawler, Z. Qiao, J. Zhou, D. Fairen-Jimenez, R. Q. Snurr, S. V. Ushakov, A. Navrotsky, C. M. Brown and P. M. Forster, J. Phys. Chem. C, 2013, 117, 20116.

5 O. V. Magdysyuk, F. Adams, H.-P. Liermann, I. Spanopoulos, P. N. Trikalitis, M. Hirscher, R. E. Morris, M. J. Duncan, L. J. McCormick and R. E. Dinnebier, Phys. Chem. Chem. Phys., 2014, 16, 23908.

6 A. Vishnyakov, P. I. Ravikovitch, A. V. Neimark, M. Bulow and Q. M. Wang, Nano Lett., 2003, 3, 713; A. I. Skoulidas, J. Am. Chem. Soc., 2004, 126, 1356; J. A. Greathouse, T. L. Kinnibrugh and M. D. Allendorf, Ind. Eng. Chem. Res., 2009, 48, 3425; R. Krishna and J. M. van Baten, Langmuir, 2010, 26, 3981; E. Pantatosaki, F. G. Pazzona, G. Megariotis and G. K. Papadopoulos, J. Phys. Chem. $B$, 2010, 114, 2493; P. Ryan, O. K. Farha, L. J. Broadbelt and R. Q. Snurr, AIChE J., 2011, 57, 1759; P. J. Ryan, O. K. Farha, L. J. Broadbelt, R. Q. Snurr and Y.-S. Bae, US Pat., US 2014/ 0013943 A1, 2014; B. J. Sikora, C. E. Wilmer, M. L. Greenfield and R. Q. Snurr, Chem. Sci., 2012, 3, 2217; T. Van Heest, S. L. TeichMcGoldrick, J. A. Greathouse, M. D. Allendorf and D. S. Sholl, J. Phys. Chem. C, 2012, 116, 13183; Y. Gurdal and S. Keskin, Ind. Eng. Chem. Res., 2012, 51, 7373; Y. Gurdal and S. Keskin, J. Phys. Chem. C, 2013, 117, 5229; M. V. Parkes, C. L. Staiger, J. J. Perry IV, M. D. Allendorf and J. A. Greathouse, Phys. Chem. Chem. Phys., 2013, 15, 9093; Q. Wang, H. Wang, S. Peng, X. Peng and D. Cao, J. Phys. Chem. C, 2014, 19, 10221.

7 U. Mueller, M. Schubert, F. Teich, H. Puetter, K. Schierle-Arndt and J. Pastre, J. Mater. Chem., 2006, 16, 626; A. Boutin, M.-A. SpringuelHuet, A. Nossov, A. Gedeon, T. Loiseau, C. Volkringer, G. Ferey, F.-X. Coudert and A. H. Fuchs, Angew. Chem., 2009, 121, 8464; D. Farrusseng, C. Daniel, C. Gaudillère, U. Ravon, Y. Schuurman, C. Mirodatos, D. Dubbeldam, H. Frost and R. Q. Snurr, Langmuir, 2009, 25, 7383; P. K. Thallapally, J. W. Grate and R. K. Motkuri, Chem. Commun., 2012, 48, 347; J. Liu, P. K. Thallapally and D. Strachan, Langmuir, 2012, 28, 11584; S. T. Meek, S. L. TeichMcGoldrick, J. J. Perry IV, J. A. Greathouse and M. D. Allendorf, J. Phys. Chem. C, 2012, 116, 19765; C. A. Fernandez, J. Liu, P. K. Thallapally and D. M. Strachan, J. Am. Chem. Soc., 2012, 134, 9046; Y.-S. Bae, B. G. Hauser, Y. J. Colón, J. T. Hupp, O. K. Farha and R. Q. Snurr, Microporous Mesoporous Mater., 2013, 169, 176; K. V. Lawler, Z. Hulvey and P. M. Forster, Chem. Commun., 2013, 49, 10959; H. Wang, K. Yao, Z. Zhang, J. Jagiello, Q. Gong, Y. Han and J. Li, Chem. Sci., 2014, 5, 620; J. J. Perry IV, S. L. Teich-McGoldrick, S. T. Meek, J. A. Greathouse, M. Haranczyk and M. D. Allendorf, J. Phys. Chem. C, 2014, 118, 11685; J. Liu, D. M. Strachan and P. K. Thallapally, Chem. Commun., 2014, 50, 466.

8 A. Soleimani Dorcheh, D. Denysenko, D. Volkmer, W. Donner and M. Hirscher, Microporous Mesoporous Mater., 2012, 162, 64.

9 D. Denysenko, M. Grzywa, M. Tonigold, B. Streppel, I. Krkljus, M. Hirscher, E. Mugnaioli, U. Kolb, J. Hanss and D. Volkmer, Chem. - Eur. J., 2011, 17, 1837.

10 D. Denysenko, M. Grzywa, J. Jelic, K. Reuter and D. Volkmer, Angew. Chem., 2014, 126, 5942 (Angew. Chem., Int. Ed., 2014, 53, 5832).

11 J.-L. Hodeau, P. Bordet, M. Anne, A. Prat, A. N. Fitch, E. Dooryhee, G. Vaughan and A. Freund, Proc. SPIE, 1998, 3448, 353; J. P. Wright, G. B. M. Vaughan and A. N. Fitch, IUCr Computing Commission Newsletter, 2003, 1, 92.

12 H. M. Rietveld, Acta Crystallogr., 1967, 22, 151; H. M. Rietveld, J. Appl. Crystallogr., 1969, 2, 65. 